\title{
MARATHON VOLLEYBALL: CHANGES AFTER 61 HOURS PLAY
}

\author{
P. M. LUND, MD
}

Sports Medicine Clinic, Hvidovre, Copenhagen

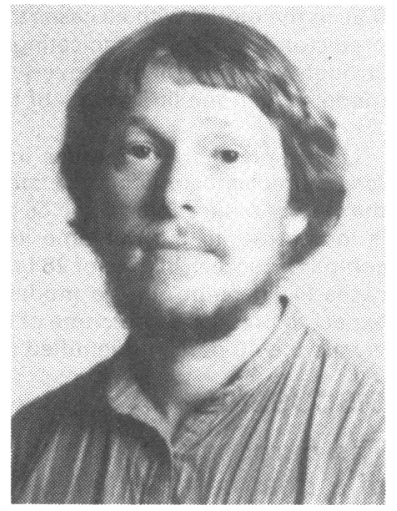

P. M. Lund

\section{ABSTRACT}

A description of symptoms after long-standing physical activity has been the purpose of this study. Twelve healthy, well trained young men who participated in a marathon volleyball game were interviewed and examined 1 day, 1 week and 5 weeks after the game, which lasted 61 hours, 23 mins. During the game, and on the day after, different psychological symptoms appeared. These had all disappeared by the second day.

Somatic symptoms were dominated by over-strain injuries to the locomotor system. At the first, second and third examinations the total number of injuries were 29, 26 and 9 respectively. These symptoms were diminishing in spite of continued physical activity and it is suggested that over-strain injuries might be sufficiently treated by moderate activity instead of recommending a period of total cessation from sports activities.

Key words: Over-strain injuries, Volleyball, Sleep deprivation, Exercise, Fatigue.

\section{INTRODUCTION}

The effect of prolonged sports performances has been investigated in earlier works considering single parameters (Bugge et al, 1979; Martin, 1981; Opstad et al, 1980, 1978; Todor, 1975). The incidence and type of over-strain symptoms has only been described in relation to sports of more conventional duration (Caldwell, 1981; Gruchow and Pelletier, 1979; Welsh and Clodman, 1980). Thus the purpose of the present report has been to give a general description of symptoms occurring during a 5 weeks period, following a marathon volleyball game.

\section{METHODS}

In August 1982 a Danish volleyball team tried to beat the existing world record in a marathon volleyball game. This is, according to the Guinness Book of Records, 75 hours and 30 minutes.

The two teams consisted of 6 healthy and well-trained, male volleyball players in each team, whose average age was 22.1 years (age range 19-28 years). During the game they were allowed two intervals, each of 30 sec, per team per set (average 3 sets/hour). Furthermore each player was given 5 mins per hour for eating, drinking, toilet-visits, etc.

The game was interrupted after 61 hours, 23 minutes due to different psychological disturbances. The day after, the players were questioned about physical and psychological symptoms during and after the game. They underwent a general medical examination including temperature, pulse, blood-pressure, weight and urinary screening for protein, blood and glucose. This was repeated 1 week and 5 weeks after the game.

\section{Address for correspondence:}

Dr. Poul M. Lund

Espegårdsvej $28 \mathrm{~A}$

DK-2880 BAGSVAERD

Denmark

\section{RESULTS}

Most of the players found the game moderately uncomfortable. Only 3 of them were willing to repeat the game under similar conditions at a later time. They were all satisfied to have had the experience as they all felt they had come better to know their own ways of reacting, during the game. During the game different psychological and physical disturbances appeared. As to the psychological disturbances, these were dominated by intermittent periods of shortlasting hallucinations and delusions. These experiences were related to the room and the game and comprised, for 11 of the players, a conviction of playing in 2 different rooms. This could later be stated to have been caused by the different appearances of the room during day/night. As to the 12th person he too had had this perception, but in contrast to the others he had been able to realise that it was a delusion. Besides these delusions several players in periods had perceived the ball as quite a different object, for instance as a dead fish, a claypot, a small summer cottage, a decoy, etc. Two players presented persecutive paranoic symptoms: one thought the others were trying to kill him and the other perceived a clock on the wall as a magic eye keeping him under control. As a result of these disturbances the game was interrupted after 61 hours and 23 minutes.

At the examination the day after, all of the mentioned symptoms had completely disappeared and 11 were found psychologically normal whereas one was clearly depressive without a self-recognised reason, and with a tendency to cry. No suicidal impulses or neurotic characteristics were found. He had never before had similar symptoms or other psychological disturbances and there was no family-history of depressions. It turned out that in contrast to the others he had had difficulties in falling asleep the night after the game. He contacted a psychologist and was treated by relaxation the next morning, after which he fell asleep. The morning after he was found psychologically normal.

All the players complained of ill-defined fatiguesymptoms such as slow-cerebration, difficulties to concen- 
trate and slight headaches. These symptoms kept on for an average of 3-4 days. At the one week control all 12 players still felt less fit during training than usual. At the five-weeks control only two felt not to have reached their former level of physical fitness.

Physical examination revealed normal findings from the respiratory system, cardiovascular system and digestive tract. Two of them had a fine hand tremor at the first control and two had traces of urinary protein. These symptoms had disappeared at the one week control. Five players showed no weight change the day after the game had finished while one had regained weight after 1 week and three after 5 weeks. After 5 weeks three players still had not regained weight.

As to the locomotor system the symptoms were located mainly in the legs and feet and were of over-strain type (Table I). Symptoms which were reported by the players to have been present before the game, have been omitted from the investigation.

Table I shows that some of the over-strain symptoms are not revealed until the one-week control but otherwise symptoms seem to disappear with time in spite of intensive exercise (at least 9 hours/week). Thus at the first, second and third examination, a total number of injuries were found to be 29,26 and 9 respectively.

TABLE I

Types and numbers of over-strain injuries in 1 day, 1 week and 5 weeks after the game

\begin{tabular}{lccc}
\hline Time after the game & 1 day & 1 week & 5 weeks \\
\hline Tender heel pad & 4 & 0 & 1 \\
Fasciitis plantaris & 1 & 1 & 0 \\
Tenderness of caput metatarsi II & 3 & 2 & 2 \\
Tendinitis m tibialis post. & 0 & 2 & 0 \\
Tendinitis Achilles & 6 & 4 & 2 \\
Myosis triceps surae & 3 & 0 & 0 \\
Apicitis patellae & 4 & 6 & 1 \\
Tendinitis m semimembranosi & 4 & 6 & 1 \\
Tendinitis mm adductorum fem. & 1 & 1 & 0 \\
Tendinitis m bicipitis brachii & 2 & 2 & 1 \\
Tendinitis m supraspinati & 0 & 2 & 1 \\
Tendovaginitis crepitans $\mathrm{m}$ & & & \\
flex. dig. man. & 1 & 0 & 0 \\
\hline Total & 29 & 26 & 9 \\
\hline
\end{tabular}

\section{CONCLUSIONS}

In this investigation it was found, that the psychological symptoms, presumably due to sleep deprivation, were the limiting factor as to how long time the team could keep on playing.

The more acute psychological symptoms seemed to disappear after one night's sleep whereas weak symptoms of tiredness kept on for about 3-4 days. These findings are in correspondence with earlier literature on the subject (Bugge et al, 1979; Opstad et al, 1978).

The physical injuries seemed few and reversible and were dominated by disorders of the musculo-skeletal system. It is interesting to note, that the over-strain injuries regress in spite of continued playing-activity at a rather high level. This fact seems to contradict the often recommended total cessation of sports activities in the treatment of over-strain injuries. A reduction of activity might be sufficient.

The results of this investigation are, of course, only representative for healthy, well-exercised, young men. Some investigations indicate that the number of injuries rise in relation to lack of training (Caldwell, 1981; Kurppa et al, 1979), whereas others have not been able to confirm this (Gruchow and Pelletier, 1979). There also seems to be a tendency towards more frequent over-strain injuries with increasing age (Gruchow and Pelletier, 1979).

\section{References}

Bugge, J. F., Opstad, P. K., Magnus, P. M., 1979 "Changes in the circadian rhythm of performance and mood in healthy young men exposed to prolonged, heavy physical work, sleep deprivatioon and caloric deficit". Aviat.Space Environ.Med. 50: 663-8.

Caldwell, J., 1981 "Experience from the 1980 midnight sun marathon. Injuries and training". Alaska med. 23: 18-21.

Gruchow, H. W., Pelletier, D., 1979 "An epidemiologic study of tennis elbow". Am.J.Sports Med. 7: 234-8.

Kurppa, K.,Waris, P., Rokkanen, P., 1979 "Peritendinitis and tendosynovitis". Scand.J.Work Environ.and Health 5: 19-24.

Martin, B. J., 1981 "Effect of sleep deprivation on tolerance of prolonged exercise". Eur.J.Appl.Physiol. 47: 345-54.

Opstad, P. K.,Aakvaag, A., Rognum, T. O., 1980 “Altered hormonal response to short-term bicycle exercise in young men after prolonged physical strain, caloric deficit and sleep deprivation". Eur.J.Appl.Physiol. 45: 51-62.

Opstad, P. K., Ekanger,R., Nummestad, M., Raabe, N., 1978 "Performance, mood and clinical symptoms in men exposed to prolonged, severe physical work and sleep deprivation". Aviat.Space Environ. Med. 49: 1065-73.

Todor, J. I., 1975 "Changes in depth perception during a nonstop walk of 3021/4 miles". Percept.Mot.Skills 40: 762.

Welsh, P. R., Clodman, J., 1980 "Clinical survey of Achilles tendinitis in athletes". Can.Med.Assoc.J. 122: 193-5
Title:

Author:
Publishers:

\section{HEALTH EDUCATION AND ACTIVITIES FOR OLDER PEOPLE

Miriam Bernard $\quad 1985 \quad$ ISBN 0-903160-24-2

Health Education Council \& Keele University.

Price: Not stated

67 pages A4 size

No Figs. or Index

This report reviews the current views on the necessity of improving the quality of life in the elderly, by means of eduction, self-help and the need for continuing or stating suitable physical activity. Keep-fit instructors visit Bingo Halls before play commences, schemes for exercises are being run in some hospitals, and advantage is being taken of the CCPR's Community Sports Leaders Course to enrol skilled instruction. Details are given of thirty areas in the UK in which Clubs or other schemes have been established, and we published a letter about one of these in Brit.J.Sports Med. Vol. 19 No. 1 March 1985 by Dr. Jean McHeath about developments in the Dover area, centred on Nonington College. Organisers' addresses are given for each area. There is a useful list of references, and I would consider this a valuable source of information for anyone concerned with the welfare of the senior citizen. 